\title{
Ambert, Dore-L'Église, Marsac-en-Livradois et Saint-Just-de-Baffie
}

\section{Franck Fassion}

\section{OpenEdition \\ Journals}

Édition électronique

URL : http://journals.openedition.org/adlfi/5989

ISSN : 2114-0502

Éditeur

Ministère de la culture

Référence électronique

Franck Fassion, «Ambert, Dore-L'Église, Marsac-en-Livradois et Saint-Just-de-Baffie », ADLFI.

Archéologie de la France - Informations [En ligne], Auvergne, mis en ligne le 01 mars 2007, consulté le 03 mai 2019. URL : http://journals.openedition.org/adlfi/5989

Ce document a été généré automatiquement le 3 mai 2019.

(C) Ministère de la Culture et de la Communication, CNRS 


\title{
Ambert, Dore-L'Église, Marsac-en- Livradois et Saint-Just-de-Baffie
}

\author{
Franck Fassion
}

Identifiant de l'opération archéologique : 141

Date de l'opération : 2007 (PI)

1 Cette campagne de prospection-inventaire diachronique s'intègre dans un master 2 d'archéologie à l'université Blaise-Pascal sous la direction de Frédéric Trément. Cette campagne a pour but de donner une image plus précise du peuplement de la plaine d'Ambert et des contreforts des massifs du Livradois-Forez par la découverte de nouveaux vestiges archéologiques et d'enrichir le corpusde données existantes par un géoréférencement précis des entités. Ces campagnes se sont déroulées de juin à octobre 2007. L'écartement maximum est de $10 \mathrm{~m}$. Le ramassage des artefacts présents en surface est représentatif à $10 \%$ des tessons présents qui ont été prélevés dans un contexte hors site et intégral sur site. Mon attention s'est portée principalement sur deux secteurs.

2 Le premier secteur est sur la commune de Saint-Just, sur la partie sommitale de cet éperon qui, selon les auteurs de deux sondages en 1977 et 1978, serait le lieu d'un oppidum . Cette opération s'est déroulée dans des conditions défavorables, car la végétation est essentiellement constituée de prairie à une altitude comprise entre $820 \mathrm{~m}$ et $862 \mathrm{~m}$. Bien que cette campagne n'ait pas permis de dégager des restes de remparts et de portes, de nombreux tessons ont été découverts sur le versant nord en direction du village actuel, confirmant une datation du site du $\mathrm{I}^{\mathrm{er}} \mathrm{s}$. avant notre ère au $\mathrm{II}^{\mathrm{e}} \mathrm{s}$. après. Les autres versants n'ont révélé aucun indice de présence humaine, hormis un petit bâtiment romain où ont été découvertes des tegulae au sud-est.

3 Le second secteur est situé sur les communes d'Arlanc et de Dore-l'Église où de nombreux vestiges néolithiques et gallo-romains ont été découverts au milieu des années 1980. Les conditions de prospections se sont révélées une nouvelle fois difficiles par la dominance de la prairie sur les terres labourées. Il m'a été également permis de suivre les travaux forestiers, dont les arrachages des souches d'arbres. Cependant, les parcelles prospectées 
n'ont pas permis de retrouver de vestiges, mais néanmoins un bruit de fond d'occupation gallo-romaine a été enregistré.

4 Fassion Franck

INDEX

Index géographique : Auvergne, Puy-de-Dôme (63), Ambert operation Prospection inventaire (PI)

Thèmes : habitat, occupation du sol, oppidum, tuile

Index chronologique : Moyen Âge, Empire romain, âge du Bronze, âge du Fer

\section{AUTEURS}

FRANCK FASSION

BEN 